\title{
Escondiendo la muerte: Atahualpa y Hernando de Soto en la pluma de Garcilaso
}

\author{
LUIS MiLLONES \\ Universidad Nacional Mayor de San Marcos
}

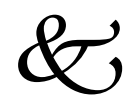

Resumen

Este artículo estudia las muertes de Hernando de Soto y Atahualpa a partir de los escritos del Inca Garcilaso de la Vega. El autor utiliza para este propósito textos como La Florida del Inca y Los comentarios reales en los que el escritor mestizo se ocupó largamente sobre ellos y sus dramáticos decesos. El interés del autor en este tema se explica por la forma de sus muertes y el destino final de sus cuerpos. Sin embargo, el autor considera que es necesario acudir a otras fuentes para enmendar algunos errores cometidos por Garcilaso.

Palabras claves: Muerte, Atahualpa, Hernando de Soto, Garcilaso de la Vega, Comentarios Reales, La Florida del Inca.

\section{Abstract}

Hiding death: Atahualpa and Hernando de Soto in Garcilaso's writings

The author relies on Garcilaso's main works to comment on the unfortunate deaths of de Soto and Atahualpa for whom the Peruvian writer had shown an especial interest. However, he deems it necessary to recur to other sources in order to correct some of Garcilaso's mistakes.

Key words: Death, Atahualpa, Hernando de Soto, Comentarios Reales, La Florida del Inca. 
En Cajamarca no sólo se encontraron dos imperios, se encontraron también dos universos de fe, que estando articulados de muchas maneras, podían ser distintos y al mismo tiempo coincidir en más de un recodo del pensamiento.

Compararlos en el estado actual de las investigaciones, resulta casi imposible. Nos podemos acercar, eso si, a partir de objetivos más modestos, pensando en algunos de los protagonistas, de quienes tenemos mayor información, y limitando al mismo tiempo los temas que pueden ser comunes entre europeos y americanos.

Dos de ellos, de Soto y Atahualpa cruzaron sus vidas por algún tiempo durante el cautiverio del Inca, y son además personajes centrales de las crónicas americanas. Coincidieron también en lo penoso de sus muertes y el destino sorprendente de sus cuerpos, ambos perdidos, uno quizá en algún escondrijo en los Andes, el otro arrastrado por las aguas del Mississippi. Los nueve años que separan a don Hernando de la muerte del Inca, no borraron de la mente del conquistador la magnitud del tesoro acumulado tras el asalto de las tropas de Pizarro. Esa obsesión lo llevó a la tumba.

Garcilaso de la Vega escribió sobre ambos muchas páginas, en especial las consagradas a de Soto, a quien dedicó La Florida del Inca, pero también dejó noticia sobre Atahualpa, que protagonizó los primeros capítulos de su Segunda Parte de los Comentarios Reales de los Incas. A continuación usaremos a este autor como marco referencial de las circunstancias de la muerte de nuestros personajes, pero no será la única fuente. Dado el propósito de este ensayo, otras crónicas y estudios críticos cubrirán las omisiones y equivocaciones históricas del escritor mestizo.

\section{Atahualpa}

En abril de 1535 los europeos vieron la única ceremonia incaica de la que hasta ahora tenemos noticia directa. Dice el cronista (Molina, El almagrista, 1968: 82), que a la salida del sol, en las afueras del Cuzco, se realizaba el espectáculo que alcanzó a ver y que estaba dedicado al dios Sol por la cosecha pasada. "A tiro de herrón»se armaban «tolderías», una frente a otra, en la primera estaban los «bultos» 
[cuerpos momificados de los nobles e incas muertos] cada uno de ellos tenía allí gran servicio de hombres que todo el día les estaban mosqueando [espantando las moscas] con unos aventadores de plumas de cisnes de espejuelos y sus mamaconas, que son como beatas; en cada toldo había como doce o quince. (Ibid: 82) En realidad se trata de tiendas o adoratorios que podían armarse a campo abierto, Soto se llevó uno similar a éstos, muy lujoso (también tomado de los incas), a su expedición en Norteamérica para su uso personal, que duró muy poco. (Duncan, 1996: 270)

Las que viera nuestro cronista en el Cuzco, «eran de pluma, muy ricos y bien obrados, que parecían muy bien», los cuales albergaban a las momias con sus servidores y mamaconas. No todos tenían ese privilegio, el almagrista notó que sólo "los de más autoridad ponían debajo de toldos». (Ibid: 82) La ceremonia duró hasta el ocaso y la fiesta un total de ocho días, y lo más interesante es que cada toldería, la de los incas vivos y la de los incas muertos, tenía un coro que cantaba siguiendo la voz que daba el Inca gobernante, que por supuesto, estaba con los nobles, frente a las momias de sus antecesores. La idea de este intercambio de voces resulta muy significativa de la religión de los incas y de la participación de los muertos en el universo ceremonial. $\mathrm{Al}$ responder -con las voces de su coro- los malquis (tal es el nombre de las momias de los incas muertos) dan cuenta de su vitalidad y de su voluntad de seguir presentes como parte de la clase dirigente.

En realidad lo que vio nuestro informante fue una situación irrepetible por las avatares de la Conquista y de las guerras civiles entre los conquistadores. Se trataba de las panacas reales, es decir conjuntos familiares que se formaban a la muerte de cada Inca, y que se agrupaban en torno al cuerpo momificado del difunto para constituir un grupo de poder. A partir de ese conjunto de nobles, poseedores de edificios suntuosos, tierras y servidores de distinto calibre, el Inca muerto seguía siendo influyente. Su familia, que se comunicaba con él a través de un servidor especializado, decía recoger las opiniones y mandatos del malqui (palabra que también alude a la semilla) y compartía con las otras familias la capacidad de conversar con quien ejercía el gobierno, o Sapa Inca, para tomar las decisiones sobre la multitud de súbditos y aliados en los extensos límites del 
Tahuantinsuyu. Ser un malqui, o momia reverenciada era el destino de todo inca. Una vez difunto, su cuerpo seguiría siendo objeto de cuidado, hablaría por boca de otros y en cierta forma derrotaría a la muerte. Eso es lo que esperaba que sucediese con su cuerpo. El hijo de Huayna Capac, acababa de derrotar a su medio hermano Huascar y no se detendría hasta llegar al Cuzco. Quienes se habían opuesto estaban recibiendo su castigo, el peor de ellos era arrastrar la momia a la que servían y destrozarla o quemarla para que no quedase memoria de su existencia. Más tarde, al hacer la capaccuna o relación de incas, sus nombres habrían sido borrados, sus propiedades demolidas o redistribuidas y su familiares masacrados todos, en una orgía de sangre, para evitar herederos y recuerdos molestos. (Santillán, 1968: 112; Millones, 1982: 245; Andrien, 2001: 28)

La idea de relacionar el cuerpo momificado con la semilla, no es incaica, tiene cientos o quizá miles de años de antiguiedad en el área andina. Se expresa también en la iconografía. Un ejemplo claro aparece en la cerámica de Nazca, donde se ve brotar plantas de las cabezastrofeo. Los miembros de una panaca se comportaban como los nuevos brotes del malqui o semilla. A su vez el cuerpo yerto de la momia recibía vida del comportamiento de su gente, y de la aceptación tácita del resto de panacas. Pero si el juego de alianzas y tradiciones que demanda el ejercicio del poder hacía que el malqui cayese en desgracia, se corría el riesgo que la panaca entera fuese exterminada.

Es posible que este culto a los ancestros, que era común a la mayoría de las etnías del área andina, haya desarrollado también las estrategias de preservación de los malquis, en caso de persecución. Eso explicaría la capacidad de esconder las momias (de sus líderes regionales), y el número de ellas que descubrieron tardíamente los evangelizadores, e incluso las que todavía sobreviven a la búsqueda ilegal de los huaqueros o saqueadores de tumbas. Si esto es así, la muerte de Huascar narrada por Garcilaso resulta creíble por el interés de Atahualpa en desaparecer su cuerpo: «Matáronle crudelísimamente haciéndole cuartos y tasajos, y no se sabe donde lo echaron: créese entre los indios que se los comieron de rabia. El Padre Acosta dice que lo quemaron». (Garcilaso, 1960: 63) Otros relatos, más escuetos, no dejan de mencionar su dolorosa muerte "por orden del dicho Atahualpa Inca, los mató a 
Huascar Inca en Antamarca, y así mismo a su hijo, mujer y madre, con gran crueldad». (Santa Cruz Pachacuti, 1968: 318) En todo caso, sea que arrojaron sus restos al río, como dicen otras fuentes o se lo devoraron como supone Garcilaso de la Vega, el cuerpo de Huascar no existía y por tanto no era posible ninguna forma de reverencia.

La participación en los asuntos de estado de las momias y su entorno había sido constante en los años anteriores a Pizarro, y probablemente mucho tiempo atrás. Fue así como Huayna Capac tuvo que renunciar a una mujer que pretendía porque el malqui de su padre Tupac Yupanqui le negó la autorización de hacerlo. (Santa Cruz Pachcacuti, 1968: 308) A su vez, su propio malqui se casó con Mama Rawa Ocllo (madre de Huascar), acción que ha sido interpretada como un intento de legitimar las ambiciones de Huascar al gobierno del Tahuantinsuyu. (Santa Cruz Pachacuti, 1968: 311)

\section{La muerte del Inca}

No es éste el lugar para repetir la jornada de Cajamarca. El sábado 16 de noviembre de 1532 el Tahuantinsuyu se quedó sin gobierno, luego de varios años de guerra que dejaron a un Inca preso y luego ejecutado, y al otro en camino de seguir sus pasos, sin siquiera haber llegado a la capital de lo que podría haber sido su imperio. El desconcierto de la población, situada en cualquiera de los dos bandos, ha debido ser total. Capturados y ejecutados ambos, el poder pasaba de la indecisión a la vacancia absoluta. A lo que se sumaba la invasión de seres extraños, cuyas acciones eran incomprensibles, salvo el terror que infundía su maquinaria militar: caballos, perros de guerra, armaduras y armas de fuego, todo ello hacía difícil pasar del pasmo a la defensa.

Los ocho meses y días que sobrevivió cautivo, Atahualpa se esforzó en entender a sus enemigos y de conseguir su libertad. Pero era una ilusión imposible. Pizarro y sus hombres empezaron a descubrir la magnitud de la empresa felizmente lograda y la importancia de su rehén. Mientras sucesivas expediciones al Cuzco y Pachacamac les daban una idea de las proporciones del imperio y de la contienda entre los hijos de Huayna Capac, Atahualpa tenía el valor de rey cautivo. Pero cuando la información básica necesaria fue lograda y su presencia podía 
atraer potenciales intentos de rescate, su presencia en la hueste aumentaba el riesgo de los europeos. Por unas semanas funcionó el argumento de las piezas de oro y plata ofrecidas a cambio de su libertad, pero es difícil de creer que en algún momento esta promesa tuviera alguna validez.

Garcilaso describe con la prestancia de su pluma, la serie de intrigas que rodearon su prisión, dando la imagen de que existían personas en favor del Inca (como Hernando Pizarro) y de quienes estaban en contra de él (como Diego de Almagro), pero si las disputas existieron, tenían como primer motivo el reparto del tesoro conseguido, la validez de los acuerdos anteriores y la posibilidad de adquirir mayor riqueza. En este juego de ambiciones, la vida del Inca era una pieza menor. «El cual estaba con gran temor de su muerte viendo el descontento y desabrimiento que los españoles traían unos con otros y las muchas porfías que a gritos y voces por horas y momentos entre ellos había. (Garcilaso, 1960: 64) A esto se sumaron los agüeros: «supo de sus indios que de noche corrían muchas estrellas grandes y chicas, en las cuales y en otras cosas menores aquella gentilidad en tiempos menos calamitosos miraba muy mucho para decir sus supersticiones... A lo último, para su total desesperación le dijeron que entre otras señales que el cielo mostraba, era una gran cometa verdinegra poco menos gruesa que el cuerpo de un hombre y más larga que una pica, que de noche parecía, como la vieron poco antes de la muerte de su padre Huayna Capac... como la hubiese visto y notado, se puso muy triste y no habló ni conversó más con nadie como solía». (Ibid: 64-65) Incluso, el escritor añade una nota dramática al poner en la boca de Atahualpa un réplica a Pizarro, que estaba indagando acerca de su silencio: «Apu (que es capitán general), yo estoy certificado que mi muerte será muy presto sin haber gozado de mis reinos estoy triste; porque estas señales no se muestran sino para anunciar grandes calamidades, muertes de reyes, destrucción de imperios. Todo lo cual sospechaba yo antes viéndome en cadenas de hierro, mas ahora me lo ha certificado de veras la cometa. Habías entendido la causa de mi tristeza y la razón que tengo de tenerla». (Ibid. 65)

El 26 ó 29 de julio de 1533, fecha que tiene versiones contradictorias, Atahualpa fue ejecutado. Se le dio garrote (es decir, se le asfixió con 
una soga atada a su cuello, a manera de torniquete) luego de que se le bautizó y encomendó sus hijos al propio Pizarro. Había sido sentenciado a la hoguera, pero dado que murió cristianizado se le conmutó la sentencia. De todas maneras, para cumplir la ley «se le arrimó al fuego de modo que se le quemara parte de la ropa y de la carne». (Hemming, 1983: 85) El mismo autor recoge la información de Pedro Cataño que registra la pregunta de Atahualpa sobre el destino y lugar de entierro de los cristianos y el de los indígenas. La respuesta, si tal diálogo existió, pudo ser un factor en la decisión de bautizarse. Lo que en realidad nos dice que ser quemado en esta vida o en el fuego infernal era inaceptable, pensando en el destino de su malqui. (Ibid. 85)

Las escenas de dolor, sobre todo la de sus esposas, fueron interpretadas por los cronistas como la tradición de ser enterradas con el mandatario muerto, de lo que no hay certeza en el caso incaico. La situación ha sido una práctica muy bien documentada en los señores de la costa norteña. El cuerpo de Atahualpa quedó expuesto hasta el día siguiente, que se le enterró en la improvisada iglesia de Cajamarca. No duró mucho allí, «luego que los españoles salieron de aquella provincia para irse al Cuzco, desenterraron los indios el cuerpo de su rey, porque les pareció que a la majestad de su Inca era indecente y contra su costumbre de sus pasados quedar enterrado en una pobre sepultura debajo de tierra. También lo hicieron por cumplir su mandado, que como se ha dicho, mandó enterrarse en Quito, donde lo llevaron los suyos con es poca solemnidad y pompa que como gente ya rendida a otro imperio pudieron hacer». (Garcilaso, 1960: 83)

Según nuestro escritor, en Quito, uno de sus generales, Rumiñahui, preparó un funeral abreviado de quince días, lo que según él, debió durar un año. En realidad, la pista del cuerpo se pierde luego de su desentierro, no hay otro cronista que nos hable de las exequias de Atahualpa. Resulta lógico pensar que la comitiva que portaba al Inca muerto se dirigiese a Quito ya que fue allí donde residió antes de iniciar su guerra con Huascar , y era donde mantenía su mejor audiencia, pensando además, que los españoles habían partido hacia el Cuzco.

Cualquiera que haya sido el destino del ahora Francisco Atahualpa, no sería el que avizorara el cronista testigo de la fiesta incaica al honor al Sol. Como la de Huascar, por diferentes razones, la panaca de Atahualpa 
LUIS MILLONES

había quedado sin conformarse, sus esposas y sus hijos serían dispersos en manos de los invasores. No habría, pues canciones, ni toldos, ni mamaconas, ni muerto ni vivo había podido llegar al Coricancha.

\section{En busca de Cibola}

Bajo los estatutos promulgados en Bologna en 1422, los cadáveres que podían ser usados para los estudios de anatomía tenían que provenir de una distancia inferior a treinta millas. Similares prohibiciones se establecieron en Génova, Perugia, Pisa, Florencia y Padua, lo más probable es que se tratase de evitar el tráfico de cadáveres, muy necesitados en los centros universitarios. La antiguiedad de estos reglamentos puede ser mayor en Europa Occidental, así como las disposiciones, referentes al origen de estos cuerpos, que en su mayoría provenían de los delincuentes ejecutados, tras los juicios correspondientes. En Inglaterra, se legisló mucho más tarde sobre lo que ya era una creencia popular muy extendida en el continente: la pena de muerte se consideraba más dura si además del castigo, se disponía que el cuerpo del difunto, en lugar de ser enterrado, pasase a las manos de un disector o anatomista para su uso correspondiente. En 1505 el gremio de cirujanos y barberos de Edimburgo recibió el permiso para disponer del cuerpo del delincuente ejecutado una vez al año; en 1540 fueron cuatro los cadáveres que podía usar el gremio de Londres, mientras que en la Universidad de Oxford, desde 1549, los estudiantes de medicina tenían que haber observado al menos dos disecciones a lo largo de sus cursos. (Sawday, 1996: 54-55)

Las instituciones mencionadas no eran las únicas en disputarse el cadáver recién salido del cadalso. Un clandestino pero muy importante factor estaba presente en estas luctuosas ceremonias: la brujería. Las propiedades de las diversas partes del patíbulo (en especial la soga, si se trataba de la horca) y también las partes del cuerpo del ajusticiado, habían sido codificadas en el sistema de creencias de la Edad Media y eran usadas como medicinas, amuletos, talismanes o para producir o defenderse de los maleficios.

En España y América colonial, la Inquisición era el poder del estado encargado de velar contra dichas prácticas, lo que nos dice de la vigencia 
de las mismas. Ellas eran parte de la estrategia diabólica que pretendía el cuerpo y alma de los condenados. El cuidado que se requería en los momentos finales de la vida, no sólo hacía de las disposiciones de la Iglesia Católica, se asentaba también en la sólida convicción de que la falta de esmero o distracción de parientes o allegados, podría entregar un fácil botín al Enemigo. Si tal sucedía en el cadalso, era explicable porque el delincuente -era en cierta forma- un pecador público, pero sería humillante que el cuerpo o las prendas preparadas para el entierro, fueran objeto de profanación. Más tarde, el complejo de creencias sobre la muerte y el más allá se enriquecería con el caudal de las Américas.

Hernando de Soto murió el 21 de mayo de 1542 en Guachoya (hoy Lake City) en el estado de Arkansas, «a tiro de arco» del río Mississipi. El lugar está al pie de una laguna, formado por lo que fuera el meandro del río, no muy lejos de su desembocadura. La región estaba poblada por indígenas de la cultura Caddo, que con las de Mississipi y Plaquemine dominaban la cuenca del río. A los 42 años, el conquistador había vivido y recorrido muchos mundos, incluso más que la mayoría de los que como él, llegaron al Nuevo Mundo en busca de gloria y fortuna. A mediados de mayo de 1539 había firmado su testamento, dando poder notarial a su esposa Isabel de Bobadilla, debió ser antes del día 18 de mayo, que partió en la que sería su última aventura.

En el documento especificaba cuidadosamente la forma en que sería enterrado: debían gastar dos mil ducados en construir una lujosa capilla donde se ubicaría su sepulcro, en la iglesia de San Jerez de los Caballeros, pueblo situado al NO de Sevilla, que en esa época tendría unos ocho mil habitantes.

Como otros conquistadores, Soto eligió el pueblo de su infancia, probablemente donde nació, aunque el Inca Garcilaso haya supuesto que fue natural de Villanueva de la Bancarrota. Volviendo al testamento, don Hernando dispone que su cuerpo debía reposar dentro de una tumba muy decorada, con los restos de sus padres a cada lado. Al conquistador se le colocaría en el centro de la capilla, de tal forma que los pies del sepulcro coincidan con la piedra ubicada el pie del altar. También ordenó que se coloque sobre su tumba cierto paño fino, en medio del cual debiera lucirse la cruz roja de la Orden de los Caballeros de Santiago, que sería usada durante los días de semana y otro paño 
mortuorio de terciopelo negro, con la misma cruz roja en el medio de cuatro escudos de armas de brocado (tela entretejida en oro). Estos escudos de armas deberían además, decorar la capilla en el panel que se coloca detrás y encima del altar, también en la baranda y en la sabanilla (cubierta exterior del lienzo con que se cubre al altar) de tal manera que el patrón (o sea Soto) y sus albaceas aparezcan de manera más conveniente. (Duncan, 1997: 7)

Semejante despliegue de poder, era difícil de esperar de quien llegó al Nuevo Mundo, a los diecisiete o dieciocho años sin un solo maravedí. Correspondía en cambio a quien, como don Hernando, había sido gobernador de Cuba, caballero de Santiago, con méritos y fortuna forjados en la compañía de Vasco Núñez de Balboa en Panamá, de Francisco Pizarro y Diego de Almagro en Perú, siendo además yerno del inacabable Pedro Arias de Avila, y dueño de una fortuna calculada entre 120,000 y 200,000 pesos de oro (castellanos), lo que -salvando las distancias- podría ser hoy entre ocho y medio y trece millones de dólares. Garcilaso de la Vega lo dice de mejor manera: «y aunque con esta cantidad de tesoro (que entonces, por no haber venido tanto de Indias, como después de acá se ha traído, valía más que ahora), pudiera comprar en su tierra... mucha más hacienda que al presenta se puede comprar porque entonces no estaban las posesiones en la estima y valor que hoy tienen [La Florida fue escrita entre 1592 y 1594], no quiso comprarla, antes levantando los pensamientos y el ánimo con la recordación de las cosas que por él habían pasado en el Perú, no contento con lo ya trabajado y ganado mas deseando emprender otras hazañas iguales o mayores, si mayores se podían, se fue a Valladolid, donde entonces tenía su Corte el emperador Carlos Quinto, rey de España, y le suplicó le hiciese la merced de la conquista del reino de la Florida (llamada así por haberse descubierto la costa día de Pascua Florida), que la quería hacer a su costa y riesgo, gastando en ella su hacienda y vida, por servir a Su Magestad y aumentar la corona de España». (Garcilaso, 2002: 66)

Gran parte del dinero de Soto provenía del rescate de Atahualpa, que de acuerdo con el mismo Garcilaso alcanzó a 4'605,670 ducados (1960: 72). «De esta cantidad, y de las ventajas como a tan principal capitán se le hicieron, y con lo que en el Cuzco le presentaron cuando 
él y Pedro del Barco solos fueron a ver a aquella ciudad, y con las dádivas que el mismo rey Atahuallpa le dio (ca fue su aficionado por haber sido el primer español que vio y habló), hubo este caballero más de cien mil ducados de parte (Garcilaso, 2002: 66). Lo cual ya constituye una fortuna dado que un ducado a 375 maravedíes y un peso de oro era 1.2 ducados, algo así como 55.61 dólares de nuestros días.

La nueva aventura de Soto, en la que comprometía gran parte de su fortuna, era la gobernación que combinaba las concesiones hechas anteriormente a Pánfilo Narváez y Lucas Vázquez de Ayllón y en teoría abarcaba todo lo que quedaba al Norte del virreinato de México. En realidad, por la precariedad de los mapas, nadie sabía los espacios a ser conocidos por la hueste española. Tanto es así que desde la propia capital mexicana el virrey Antonio de Mendoza, el mismo año de la partida de Soto, recibía La relación del descubrimiento de las siete ciudades, producto de las exploraciones de Fray Marcos de Niza, lo que le animaría a apoyar la expedición de Francisco Vázquez de Coronado en lo que ahora es el SO de Estados Unidos.

No dejó de enterarse don Hernando de los planes del virrey y «no sabiendo.. que parte la enviaba y temiendo no se encontrase y estorbase los unos a los otros y hubiese discordia entre ellos, como la hubo en México entre el marqués del Valle, Hernando Cortés y Pánfilo Narváez, que en nombre del gobernador Diego Velazquez había ido a tomarle cuenta de la gente armada que le había entregado, y como la hubo en el Perú entre los adelantados don Diego de Almagro y don Pedro de Alvarado a los principios de la conquista de aquel reino. Por lo cual y por excusar la infamia del vender y comprar la gente, como dijeron de aquellos capitales, le pareció a Hernando de Soto sería bien dar aviso al visorrey de las provisiones y conduta de que Su Magestad le había hecho merced para que lo supiese, y juntamente suplicarle con ellas». (Garcilaso, 2002: 97-98) Mendoza era muy hábil en este juego de ambiciones y esperanzas y le contestó que la Florida era «tan larga y ancha que había sitio para todos». (Garcilaso 2002: 98), respuesta con la que Soto tuvo que contentarse. Lo curioso de este diálogo, es que el azar hizo que Vázquez de Coronado y Soto estuviesen a punto de encontrarse, descansando ambos en Kansas (Vazquez en Tabás y Soto en Coligua), en ese punto el protegido de Mendoza decidió regresar 
aceptando su fracaso, mientras que Soto prosiguió su marcha enloquecida hacia Arkansas, donde lo detendría la muerte.

Pocas expediciones empezaron también pertrechadas como la que nos preocupa, de Cuba salieron por lo menos cinco barcos grandes, tres carabelas y varios bergantines, la expedición contaba con 620 hombres y 223 caballos como nos lo asegura uno de los pocos cronistas que acompañaron al conquistador (Hernández de Biedma, 1993: 225). Con ellos desembarcaron en Baya Honda, en lo que hoy podría ser Tampa Bay, dando inicio a su periplo un 25 de mayo de 1539, que concluiría el 10 de septiembre de 1543, cuando 311 sobrevivientes regresaron a Pánuco (México), asombrando a los vecinos por su aspecto miserable y lo rústico de sus improvisadas embarcaciones, cuando todos ya los daban por muertos. Luis de Moscoso, a quien Soto confió el mando poco antes de morir, conducía este triste regreso. La búsqueda de un nuevo Tenochtitlan o un nuevo Cuzco había concluido un año antes para don Hernando.

El relato del Inca Garcilaso de la Vega le da un sesgo épico a la «entrada» de Soto. Cualquiera que hayan sido las versiones de Gonzalo Silvestre, su principal informante y los textos de los soldados Alonso de Carmona y Juan Coles ("testigos de vista» los llama el Inca), es evidente que la Florida nace de la pluma del peruano. El relato es la epopeya de Soto, cuya persona aparece glorificada como la esencia de las virtudes del conquistador-caballero. Otros cronistas de las aventuras de la Florida ha dejado versiones discordantes, no tanto el Caballero de Elvas (1932), anónimo portugués que intentó un relato con diálogos y discursos construidos muchos años después del evento, pero más bien los otros dos compañeros de Soto: Rodrigo Rangel, cuyo texto hay que entresacarlo de la crónica de Gonzalo Fernández de Oviedo (1851) y Luis Hernández de Biedma (1993), factor real, ambos con una mirada un tanto crítica de las obsesiones y de los pillajes ordenados por el jefe de la expedición.

Es interesante anotar que el larguísimo recorrido de la hueste en pos de su propio Dorado, puedo haberse detenido en más de un lugar propicio como para fundar un establecimiento o colonia duradero. Más adelante hubiese servido para ampliar el radio de las acciones y organizar la explotación de tierras feraces, que cruzaron en más de 
una ocasión, sin amainar el paso en que caminaban. Incluso, la propia gente de Soto se lo pidió y hasta hubo amagos de motín, aunque sin llegar a cuestionar la autoridad. Pero don Hernando fue inflexible, corrió e hizo correr a su gente detrás de sucesivas metas, en las que pensaba descubrir otro Tahuantinsuyu: Ocale, Apalache, Cofitachequi, Coosa, Tascalusa, Chicasa y Tula son los nombres, que con algunas variantes mínimas, nos entregan los cronistas, refiriéndose a cada uno de los muchos lugares en que Soto creía volver a encontrar nuevamente, el tesoro de Atahualpa.

La fascinación del conquistador es explicada de manera benigna por Garcilaso: «Esto hizo Hernando de Soto movido de generosa envidia y celo magnánimo de las hazañas nuevamente hechas en México por el Marqués del Valle don Hernando Cortés y en el Perú por el Marqués don Diego de Almagro, las cuales él vio y ayudó a hacer. Empero, como en su ánimo libre y generoso no cupiese súbdito, ni fuese inferior a los ya nombrados en valor y esfuerzo para la guerra ni en prudencia y discreción para la paz, dejó aquellas hazañas aunque tan grandes, y emprendió estotras para él mayores, pues en ellas perdía la vida y la hacienda que en las otras había ganado». (2002: 66-67)

«Generosa envidia y celo magnánimo», califica el Inca al pillaje, y masacres de indígenas de la hueste española, sus integrantes asaltaron, robaron y esclavizaron a cuanto grupo de nativos se les cruzó en el camino. El avance de Soto en busca de su Cibola fue despiadado y obsesivo y no se diferencia de otros intentos como el de Narváez y Coronado, salvo que el volumen de la tropa hacía que necesitase todas las reservas del poblado al que llegaban, tomando a las mujeres como sirvientes y a los hombres como cargadores. Toda resistencia a esta invasión era aniquilada sin vacilar.

Esta tozuda búsqueda no sólo se alimentaba de las experiencias exitosas de Cortés y Pizarro, tenían raíces más profundas en la cultura española del XVI. Un siglo más tarde todavía los escritores americanos con tintes barrocos, defendía la presencia del Paraíso bíblico en la selva peruana, cuya descripción venía imaginándose desde que Colón llegó a América. Y que incluso había sido divisado desde lo alto de una montaña, aunque el R.P. Marcos de Niza parodiando a Moisés, no había podido llegar a él. Pero alcanzó a verlo y su relato encendió otras 
muchas ambiciones. Ya había tenido descripciones de los enviados de Estebanico, el negro esclavo que acompañó a Alvar Núñez Cabeza de Vaca en su extensa jornada por Norteamérica, y que ahora dirigía al grupo de vanguardia de Niza. Pero como lo ha sugerido Ahern, «lo que pudo contemplar al fin: la etérea visión de la ciudad en la llanura más allá de su alcance [donde] jornada mito y discurso se funden»: ‘ [lo que siguen son palabras de Niza] «seguí mi camino hasta la vista de Cibola, la cual estaba asentada en el llano, a la falda de un cerro redondo. Tiene muy hermoso parescer de pueblo, el mejor de estas partes yo he visto; son las casas por la manera que los indios me dixeron, todas de piedra con sus sobrados y azuteas, á lo que me paresció desde un cerro donde me puse a vella. La población es mayor que la cibdad de México; algunas veces fuí tentado de irme á ella, porque sabía que no aventuraba sino la vida, y esta ofrescí á Dios el día que comencé la jornada...» (Ahern, 1987: 303-313)

\section{El fin del camino}

Días antes de cumplir tres años en su expedición, Soto descubrió que tampoco él llegaría a Cibola, incluso es probable que finalmente estuviese pensando en regresar a Cuba, aunque fuera sólo para reorganizar su empresa. Pero su tiempo había concluido. Poco tiempo atrás, en lo que Garcilaso llama batalla de Mavila, a la que dedica cuatro capítulos (del XXVII al XXXI), don Hernando había sido herido con un flechazo en la nalga izquierda «que con la prisa de pelear no tuvo lugar de quitarse la flecha, peleó con ella todo lo que la batalla duró, que fueron casi cinco horas, sin poder asentarse en la silla». (Garcilaso, 2002: 345) Si la herida tuvo consecuencias, no lo sabemos, y no hay noticias de golpes o lesiones posteriores de mayor gravedad. Lo cierto es que, si seguimos el relato de Silvestre, redactado por Garcilaso, no fue en mayo de 1542 sino un mes después, que el gobernador "sintió una calenturilla que el primer día se mostró lenta y el tercero rigurosísima... viendo el excesivo crecimiento de ella y, como católico cristiano, ordenó casi en cifra su testamento por no haber recaudo bastante de papel y, con dolor y arrepentimiento de haber ofendido a Dios, confesó sus pecados». (2002: 447) 
La agonía de Soto, versión Garcilaso, es una muestra del peso de las normas establecidas sobre la realidad. No sólo nombra a Moscoso como sucesor, si no que tiene tiempo de despedirse de los jefes subalternos «de dos en dos y de tres en tres» y luego de la tropa " de veinte en veinte y de treinta en treinta... En estas cosas gastó cinco días que duró la calentura recia, la cual fue siempre en crecimiento hasta el día seteno, que lo privó de esta presente vida (2002: 448)

El entierro del cadáver no era fácil, por encima de la total imposibilidad de protocolo en las condiciones en que estaban los sobrevivientes de esta aventura. Luego de tres años de marchas y contramarchas, tras el fantasma de un Dorado que se esfumaba, el gobernador de Cuba los dejaba, además en medio de un conflicto. Las etnias que Garcilaso llama guachoyas y anilcos estaban enfrentados antes y después de que Soto tratara de aliarse con unos y con otros, pero al final el único enemigo que parecían ver los indígenas era los propios españoles. Durante el conflicto que alcanzaron a participar, habían reparado en el maltrato de los restos humanos que daban los guerreros de uno y otro bando. Tal situación debió sacar a luz todos los temores que arrastraba la cultura de los españoles. Para empezar estaban rodeados de paganos hostiles, cuyas ceremonias u objetos de culto, apenas observados, eran considerados demoníacos, pero más que eso, el maltrato post mortem era una señal de su condición pecaminosa, como aquellos, que siendo arrancados del patíbulo, iban a ser objeto de una disección o terminaban desmembrados para el uso de la brujería.

Había, pues, que evitar a toda costa la profanación del cuerpo de Soto. «Por lo cual acordaron enterrarlo de noche, con centinelas puestas, para que los indios no los viesen ni supiesen dónde quedaba. Eligieron para sepultura una de muchos hoyos grandes y anchos que cerca del pueblo había en un llano, de donde los indios, para sus edificios habían sacado tierra, y en una de ellas enterraron al famoso adelantado Hernando de Soto con muchas lágrimas de los sacerdotes que a sus tristes obsequias se hallaron. (Garcilaso, 2002: 450)

Preocupados por evitar que se esparciese la noticia de su muerte, la gente de Soto hizo lo posible por no mostrar su dolor, o peor aun, fingir alegría. Si creemos a Garcilaso, hicieron correr a sus caballos 
sobre su sepultura, e incluso la anegaron para evitar que la encontrase. Pero es probable que todos estos actos no hicieron si no reafirmar la sospecha de lo que realmente había sucedido, de todas maneras don Hernando estaba ausente y era imposible que los indios aliados cautivos o servidores de la hueste, hubiesen guardado el secreto. Fue así que "pasando por el llano y por las hoyas, se iban deteniendo y con mucha atención miraban a todas partes y hablaban unos con otros y señalaban con la barba y guiñaban los ojos hacia el puesto donde el cuerpo estaba».

En desesperación, los principales de la hueste decidieron desenterrar los restos y arrojarlos al río Mississippi, que la propia expedición había «descubierto» (la desembocadura ya había sido avistaba antes, varias veces) el 8 de mayo de 1541, bautizándole como Espíritu Santo, aunque Garcilaso prefiere llamarlo río Grande. Una vez medida la profundidad del trecho elegido y simulando estar de pesca, cinco de sus allegados, de acuerdo con Moscoso y los otros jefes «determinaron sepultar en el [río] al gobernador, y, porque en toda aquella comarca no había piedra que echar con el cuerpo para que lo llevase a fondo, cortaron una muy gruesa encina y, a medida del altor de un hombre, la socavaron por un lado donde pudiesen meter el cuerpo. Y la noche siguiente, con todo el silencio posible, lo desenterraron y [lo] pusieron en el trozo de la encina, con tablas clavadas que abrazaron el cuerpo por el otro lado, y así quedó como en una arca, y, con muchas lágrimas y dolor de los sacerdotes y caballeros que se hallaron en este segundo entierro, lo pusieron en medio de la corriente del río encomendando su ánima a Dios, y le vieron irse luego a fondo». (2002: 451)

\section{Conclusiones}

No debe sorprendernos que las sociedades que creen en el más allá, tengan especial cuidado con los cuerpos de esta efímera existencia. Hace miles de años en las bandas de cazadores y recolectores, los cuerpo de los difuntos pintados con ocre (o algún otro pigmento mineral) evocaban el deseo de que la sangre volviese a fluir, para ser el motor de una vida diferente a la nuestra. Para que esto suceda los parientes, amigos o servidores del muerto, tenían que sepultar el cadáver, para esconderlo de los animales carroñeros o de los odios de otros seres humanos. Más 
adelante, no bastó con esconder el cadáver luego de decorarlo, se pudo esperar a que desapareciesen las parte blandas para practicar un segundo entierro, lo que suponía sociedades algo más complejas, con cierto sentido de continuidad, por lo menos genealógica.

Con el transcurrir del tiempo, estos entierros simples se convirtieron en ceremoniales cada vez más complicados, sobre todo si al desarrollarse las elites, reclamaron para ellas la capacidad de ser inmortales. Hubo, pues, que preparar los cuerpos para tamaña aventura. Para ello, algunas sociedades cultivaron técnicas para preservar los restos físicos del muerto, otras se esmeraron en que las tumbas fueran monumentos exquisitos, o bien usaron ambos caminos para que los restos o sus envolturas, acompañen -al menos por un tiempo- la pretensión de la nobleza y de los gobernantes.

Incas y europeos se encontraron cuando ambas civilizaciones ya tenían una larga historia. En el proceso de construir su desarrollo, habían sintetizado el saber de quienes les precedieron y las sociedades que derrotaron. Además, en la tarea de construir un imperio, ambos tuvieron que organizar un sistema de valores y creencias que siendo propio, pudiese también ser aprendido y respetado por la enorme variedad de sus súbditos.

Para Hernando de Soto la captura de Cajamarca marcó su vida de manera irremediable. Más tarde, en España, buscando la entrevista con el emperador Carlos, pudo apreciar los beneficios cosechados por Hernán Cortés, la otra cara del aventurero afortunado. Preso de estas dos experiencias, construyó la ilusión de su propio destino. De un lado, la oportunidad dichosa que amparó a Pizarro al llegar al Perú en medio de una guerra civil, que le puso el Tahuantinsuyu al alcance de sus ambiciones; de otro lado, la transición de conquistador a Marqués del Valle, rico y poderoso, que logró el de México.

Pareciera que se enorme porción del rescate de Atahualpa, nunca le sugirió la posibilidad de un retiro feliz en su tierra natal, más bien espoleó su ansiedad por una Cibola que le perteneciese. Capturado por su sueño, que era el de muchos otros, no dio señales de aceptar otra cosa que no fuesen las noticias de la proximidad de su Cuzco o Tenochtitlan. Al final, sólo la muerte pudo interrumpir la carrera sin fin en la que estaba empeñado. 
Es difícil conseguir que los pocos cronistas nos digan si Soto llegó a comprender su fracaso, su doble entierro tiene la ironía de quien termina muy lejos de los deseos expresos en su testamento, devorado por sus inútiles descubrimientos.

Para Atahualpa, si creemos a Garcilaso, Soto fue una de las pocas caras amables que vio en los meses de su cautiverio. Tratando de manejar una situación perdida, al Inca no le era posible entender el juego de pasiones que había desatado su captura. Nada podía satisfacer a los españoles, que lo querían todo, y él era un estorbo en su camino, que iban a remover con o sin rescate.

La comprensión de su muerte como episodio inevitable le debió llegar sin que el juicio y la sentencia tuvieran sentido para él. Lo que le resultaba claro -como a todo gobernante cautivo- es que había perdido y es entonces cuando sobran los razonamientos. Pizarro y Valverde le dieron la opción de la manera en que sería ejecutado, entonces apostó por su condición de noble. Convertido en malqui o momia, sus parientes podían hacerlo vivir de nuevo y rendirle homenaje, como lo había visto hacer a las panacas de su padre y de sus abuelos.

Su cuerpo puede haber tenido la suerte que le faltó a Soto, desenterrado del novísimo camposanto cristiano, quizá haya recibido el tratamiento al que aspiraba. Pero no acudirá a reunirse con otros malquis en el Cuzco, porque con él feneció también el imperio. Al menos, los familiares que raptaron su cuerpo lo deben haber colocado en algún recinto no descubierto, quizá en la cima de una montaña. Desde allí, conservado por el frío de las alturas, podrá vivir su propia eternidad.

\section{Referencias bibliográficas}

AHERN, Maureen (1989): «The certification of Cibola: Discursive strategies in Fray Marcos de Niza's descubrimiento de las siete ciudades». En Dispositio: American Journal of Semiotics and Culture. Vol. XIV, No 36-38, pp. 303-313.

ANDRIEN, KENNETH J. (2001): Andean worlds. Indegenous History, Culture and Consciusness under Spanish Rule 1532-1825. Albuquerque: University of New Mexico Press.

DE MOLINA, Cristóbal (el almagrista) (1968): «Relación de muchas cosas acaescidas en el Perú». En Crónicas peruanas de interés indígena. BAE, Vol. 209, Ediciones Atlas, Madrid, [21552?]. 
DE NIZA, Marcos (1865): Relación del descubrimiento de las siete ciudades. En Colección de documentos inéditos relativos al descubrimiento, conquista y colonización de las posesiones españolas en América y Oceanía. Vol 3, Imprenta de Manuel Quiroz, Madrid, [1539].

DE SANTILLÁN, Hernando (1968): «Relación del origen, descendencia, política y gobierno de los Incas». En BAE, Vol. 209, Ediciones Atlas, Madrid, [ca 1563].

DUNCAN, David Ewing (1996): Hernando de Soto. A savage quest in the Americas. Norman: University of Oklahoma Press.

ELVAS, GENTLEMAN (1993): «True relation of the hardships suffered by governor Don Hernando de Soto...» In The Soto Chronicles, Vol. I, Edited by Lawrence A. Clayton, Vernon James Knight, Jr and Edward C. Moore, The University of Alabama Press, Tuscaloosa and London, [1557].

FERNÁNDEZ DE OVIEDO, Gonzalo (1959): La historia general y natural de las Indias. En BAE, Vol. 117-121, Ediciones Atlas, Madrid, [1547].

GARCILASO DE LA VEGA, Inca (2002): La florida del Inca, Dastin, S.L, Madrid, [1605].

GARCILASO DE LA VEGA, Inca (1960): Historia general del Perú. Segunda Parte de los Comentarios Reales de los Incas. En BAE, Vol. 134, Ediciones Atlas, Madrid, [1617].

HEMMING, John (1982): La conquista de los Incas. Fondo de Cultura Económica, México.

HERNÁNDEZ DE BIEDMA, Luis (1993): Relation of the island of Florida presented by... In The Soto Chronicles. Volume I. Edited by Lawrence A. Clayton, Vernon James Knight, Jr. and Edward C. Moore, The University of Alabama Press, Tuscaloosa and London, [1544].

MILLONES, Luis (1982): «Brujerías de la costa / Brujerías de la sierra: Estudio comparativo de dos complejos religiosos en el área andina». En El hombre y su ambiente en los andes centrales. Editado por Luis Millones y Hiroyasu Tomoeda, Museo Nacional de Etnología, Osaka.

SANTA CRUZ PACHACUTI, Juan (1968): Relación de antigüedades de este reino del Perú... En BAE, Vol. 209, Ediciones Atlas, Madrid, [1613].

SAWDAY, Jonathan (1996): The body emblazoned. Dissection and the human body in renaissance culture. Routledge, London and New York. 